\title{
RECURRENT ENCEPHALOMYELITIS IN CHILDHOOD
}

\author{
BY \\ N. S. ALCOCK and H. L. HOFFMAN \\ From the Royal Devon and Exeter Hospital and the Royal United Hospital, Bath
}

(RECEIVED FOR PUBLICATION JUNE 27, 1961)

Acute disseminated encephalomyelitis, with its histological appearance of perivenous demyelination and cellular infiltration, has been recognized for more than 30 years, but opinions regarding its aetiology have changed considerably during this time. At first it was thought that a direct virus infection of the central nervous system was responsible. Later, when it was found that the same histological picture occurred if the disease followed vaccination, any of the exanthemata or a respiratory infection, it was suggested that these precipitating causes had activated a latent virus. This theory was discarded when it was realized that the changes were unlike those of any known neurotropic virus disease and could be reproduced in experimental animals by the injection of homologous brain tissue combined with adjuvants. It is now believed that the experimental and the naturally occurring disease are the result of an antibody-antigen reaction.

There has been a tendency to assume that the illness is self-limiting and that only a single attack occurs; but recurrent episodes are encountered on rare occasions and van Bogaert, Borremans and Couvreur (1932) and van Bogaert (1950) described two such cases in children. In one of these there was histological proof of perivascular demyelination.

The first patient (van Bogaert et al., 1932) was a child of 7 , who sustained a head injury when 5 weeks old. At the age of 5 years he developed scarlet fever and was treated with anti-scarlet fever serum. During this illness an ill-defined neuropsychiatric state occurred, with spastic gait and joint pains; this recurred at the age of $6 \frac{1}{2}$ after a further attack of scarlet fever. Four months later, during an attack of measles, a cerebello-pyramidal condition developed with coma, which was eventually fatal. The second (van Bogaert, 1950) was a girl aged 9 who had diphtheria and polyneuritis at the age of 6 . Two months later, an attack of measles was accompanied by double vision and headache, with ataxia, choreiform movements of the right arm and bilateral extensor plantar responses. She was then well for three years, but at the end of this time headache, vomiting and fever occurred and she again saw double. There was bilateral optic neuritis. Later, flaccid quadriplegia developed with right facial weakness and bilateral extensor plantar responses. She died after 14 days, and autopsy was performed. The histological findings consisted of widespread perivascular demyelination in the cerebral white matter and cellular infiltration, but no trace of a previous pathological process could be seen.

In discussing recurrent encephalomyelitis we feel that it is essential, at this stage of our knowledge, to confine ourselves to examples which occur in childhood. It may well be that the same syndrome does occur in adults. This possibility has been accepted by various authors (Stout and Karnosh, 1933; McAlpine, 1946; Miller, 1957; Ferraro, 1958). We have seen very suggestive cases. Histological proof, however, has been lacking, and one cannot therefore exclude the possibility that these conditions were due to atypical multiple sclerosis. For the purpose of this paper we are accepting the view that multiple sclerosis does not occur in young children, and we present the following cases as examples of recurrent encephalomyelitis. All these patients recovered, as did the adults already mentioned, but in our opinion the clinical findings are sufficiently convincing to justify the diagnosis.

\section{Case Reports}

Case 1. This child, a boy, was born on July 19, 1952. After a normal birth he developed without incident until August 1954, when he was 2 years old. He then had an episode of drowsiness and irritability, accompanied by left-sided ptosis and paralysis of the external rectus muscle of the left eye. The cerebrospinal fluid contained six lymphocytes and one polymorphonuclear cell per c.mm. and protein $55 \mathrm{mg}$. per $100 \mathrm{ml}$. From this illness he made a complete recovery.

In October 1955 he had an attack of dizziness and ataxia, which lasted for four days. He was then well until August 1958, when he developed chickenpox. Two weeks later, while he was walking, his legs gave way and he fell down. Severe ataxia followed and he was unable to stand or walk without falling to the left. 
There was nystagmus, left lower facial weakness and leftsided hypotonia. A ventriculogram was normal, and an electroencephalogram showed a mild but diffuse abnormality. He gradually improved and now shows only minimal ataxia. Both optic discs are very pale, but vision is $6 / 6$ partly, in both eyes and the visual fields are full. There are no other abnormal physical signs. He is educationally subnormal, but it is doubtful if his intelligence quotient is much below that of his parents.

Case 2. This boy, born on December 4, 1946, after a forceps delivery, without asphyxia or trauma, progressed normally until January 1950 , when he was 3 years old. He then developed a severe febrile illness with meningism, but the cerebrospinal fluid was normal. On getting out of bed he dragged the left leg, and he had to be taught to walk again. Initially, his speech was affected, but this returned to normal; a slight tendency to drag the left leg remained. His mentality was unaffected.

In April 1953, at the age of 6 years, he had an attack of bronchitis, followed by measles. On the day following the appearance of the rash he was comatose, but improved in the next 10 days. A month later, however. he was very wasted, with clonic rhythmic movements, extrapyramidal rigidity and he was speechless. Gradual improvement occurred, but he remained a severe athetoid. His intelligence quotient was thought to be $84 \%$ in 1953 , and $49 \%$ in 1960 , although in other respects there has been no deterioration in his condition.

Case 3. This boy was born on March 24, 1943. No details of the birth are available as he was illegitimate. He is said to have been well until January 1949 when he slipped and grazed his knee. On the following day he was dragging his left leg, and two days later it was noticed that the left arm and face were weak. He was admitted to hospital where he was found to have a left hemiplegia. His cerebrospinal fluid was normal, but the blood sedimentation rate was $29 \mathrm{~mm}$. in one hour. During three weeks in hospital his temperature at times reached $101^{\circ} \mathrm{F}$., but he eventually made a complete recovery.

In 1954 he developed epilepsy, and he has continued to have major fits up to the present time. At the age of 13 there was some behaviour disturbance and delinquency which eventually caused his transfer to a detention home.

In May 1957, at the age of 14, he complained of pain in the back. About a week later his legs became weak and numb, and in a further week there was a motor and sensory paraplegia below the level of the eighth dorsal segment. He had a septic thumb at this time. The cerebrospinal fluid contained 15 cells per c.mm. and protein $55 \mathrm{mg}$. per $100 \mathrm{ml}$. He improved steadily and in a month was walking well.

He was seen again in September 1958. For two months it had been thought that he was becoming more than usually stupid and that he had difficulty in expressing himself.

He was found to have bilateral papilloedema, a considerable degree of dysphasia, a suggestion of right-sided field defect, incoordination of the arms, right hemiparesis and bilateral extensor plantar response. $\mathrm{He}$ was incontinent and uncooperative. On this occasion the cerebrospinal fluid contained one-cell per c.mm. and protein $160 \mathrm{mg}$. per $100 \mathrm{ml}$. A brain biopsy was negative. He again gradually improved, and when examined in April 1959 he was a cheerful high-grade mental defective with bilateral extensor plantar responses.

On September 5 and 6,1960, he developed a temperature of $102 \cdot 8^{\circ} \mathrm{F}$. and a sore throat. This illness was preceded by four grand mal fits. He quickly improved, and on September 9 was given his third poliomyelitis inoculation. After this, some nominal dysphasia occurred and was still present when he was examined on September 22. There was also a right-sided inattention field defect, an increased left knee jerk and an extensor plantar response on the left.

Case 4. This boy was born on January 9, 1940. On March 16, 1949, he was admitted to an isolation hospital with the following history: Fourteen days previously he felt unwell and complained of headache. On the next day he started to vomit, and thereafter vomiting continued intermittently until his admission. He then complained of pain at the back of the neck on movement and that he could not see very well; he said that he could see his mother but not her face.

His temperature was $99 \cdot 4^{\circ} \mathrm{F}$., pulse 84 , and respirations 20 per minute. No abnormal physical signs were recorded in his heart, lungs or nervous system. On the following day the temperature settled and remained normal until his discharge. While in hospital he was at times doubly incontinent, but his general condition and vision improved until he was discharged on April 8, 1949. Examination of the blood showed a sedimentation rate of $33 \mathrm{~mm}$. in the hour, and a white blood count of 21,000 per c.mm. most of the cells being polymorphonuclear.

He was well until the middle of December 1954 when he was nearly 14 . He then complained of blurred vision in the right eye and on Christmas Day the left eye became painful. Bilateral optic atrophy was found, with defective colour vision. Visual acuity was $6 / 36$ right and 6/60 left. On January 18, 1954, he was admitted to St. Martin's Hospital, Bath. At that time both optic discs were pale, he had fine irregular nystagmus on conjugate deviation of the eyes to the right and to the left and the palate deviated to the left on movement. The cerebrospinal fluid contained protein $20 \mathrm{mg}$. per $100 \mathrm{ml}$. and less than one cell per c.mm. The Lange curve showed no change. A single carious tooth was removed while he was in hospital. He was discharged on January 28 , his visual acuity having recovered to J.1 right and J.4 left partly. It later became normal but there were bilateral central scotomata for colours.

In February 1960, when he was 20, he developed a mild coryza. Three weeks later there was pain on moving the right eye, and vision in this eye became blurred. On March 15 vision was full, but by March 22 it had deteriorated to $6 / 24$ on the right. On June 16, eight carious teeth were removed, by which time vision 
had returned to normal. During this illness the left plantar response was found to be doubtfully extensor, but apart from the bilateral optic atrophy no other abnormal physical signs were found in the nervous system.

Case 5. On May 26, 1957, this boy, born in 1951, developed measles and was kept in bed for 10 days. $\mathrm{He}$ was well in two or three weeks. At some indefinite time after this he became vaguely unwell, being lethargic with frontal headache and vomiting which occurred about twice a week. On August 21 his gait became unsteady and he was unable to walk alone. A week later he was found to have normal optic discs, nystagmus on looking to the left, a lower right facial weakness, slight incoordination of the left arm and diminished right abdominal reflexes. Ventriculography revealed normal lateral and third ventricles but no satisfactory filling of the aqueduct or fourth ventricle was obtained. On August 30 a sub-occipital craniotomy was performed. The cerebellar tonsils were prolapsed, but no tumour was found, and he was symptom-free when discharged from hospital on September 22.

On October 10, 1957, he complained of blurred vision and his visual acuity deteriorated to hand movements on the right and counting fingers on the left by October 22. In November and December he was given prednisone for three weeks and by January 8, 1958, his visual acuity had returned to $6 / 18$ right and 6/6 left. The optic discs were pale and atrophic.

In October 1959 vision again failed in the left eye but recovered after further treatment with prednisone. When first seen by one of us on March 18, 1961, he was well, attending school and playing games. There was bilateral optic atrophy, visual acuity being J.1 right and left partly. Knee and ankle jerks were exaggerated, but the plantar responses were flexor. No other abnormal signs were found in the nervous system.

Case 6. In June 1958, at the age of $5 \frac{1}{2}$, a boy, born on November 2, 1952, developed severe headache, neck stiffness, photophobia and pyrexia. He was sent to an isolation hospital where he rapidly recovered. A lumbar puncture was not performed. No organisms were grown from throat or nose swabs.

Early in August 1959 he had chickenpox as did his identical twin brother. On September 19, 1959, he was admitted to Musgrove Park Hospital, Taunton, under the care of Dr. Brian Webb. His history was as follows: Two weeks previously he developed coryza; during the week before admission his temperature rose to $101^{\circ} \mathrm{F}$., he complained of headache and photophobia, he was drowsy and his walking was unsteady.

He was quiet and apathetic but not confused. There was no neck stiffness. There was nystagmus on looking to the right but no other abnormality in the cranial nerve functions. Marked ataxia was found in all four limbs, the tendon reflexes were diminished, and the plantar responses were flexor. The cerebrospinal fluid contained protein $30 \mathrm{mg}$. per $100 \mathrm{ml}$. and four lymphocytes per c.mm. Examination of the blood showed a haemoglobin of $92 \%$; there were 6,000 white blood cells per c.mm., the differential count being normal. The sedimentation rate was $15 \mathrm{~mm}$. in one hour, and the Paul Bunnell test was negative. His temperature became normal after 24 hours in hospital and he was discharged on September 26, 1959 . At home he made rather slow progress and in January 1960 there was still a certain amount of ataxia. At about this time there was an episode of double vision which lasted for three or four hours. He also had an attack of influenza during which he again became giddy but did not see double. By March 1960 he was getting up about three hours a day and was walking well. In June 1960 he had improved still more, although his speech was still a little slurred. An electroencephalogram showed a preponderance of moderate amplitude slow activity in the left temporal and posterior regions. When seen by one of us on April 8, 1961, he had been attending school and playing games perfectly normally. No abnormality of the nervous system was found.

\section{Discussion}

In this syndrome the recurrent attacks can often be directly related to an acute infection, exanthematous or otherwise. This was particularly well seen in the cases of van Bogaert and his colleagues, which we have already quoted. Van Bogaert (1950) held the view that ' . . . the several forms of exanthematous diseases can be accompanied by neurologic complications which are always the same in the same patient, as if successive diseases reactivated the same cerebral scar'. He suggested that, in his second case, diphtheria originally 'sensitized' the nervous system and that measles subsequently 'set off an ataxia, pyramidal signs, and an involvement of the right oculomotor nerve'. In retrospect, it is sometimes possible to find evidence suggestive of this 'sensitization' of the nervous system in the previous history of patients with encephalomyelitis. For example, a boy aged 2 years and 4 months was seen with Dr. John Apley in 1958. His illness started with a pyrexia up to $105^{\circ} \mathrm{F}$. over a period of two days, and there were generalized convulsions. Twenty-four hours after the temperature subsided a transient rash appeared, followed by a well-marked cerebellar ataxia which gradually cleared up after several weeks. Three months previously he had had measles, preceded by convulsions, and remained semi-comatose for three days. This episode may well have been an encephalitic illness in which his nervous system developed the initial sensitivity. Miller (1953) gave a good example of a patient in whom the same territory was apparently involved on several occasions. He described the case of a 14-year-old boy in whom five attacks of an encephalitic illness recurred in five months. Each followed 
an upper respiratory infection, and in each episode there were almost identical symptoms. During the last of these attacks his brother was affected in the same way. Similarly, our fourth case showed recurrent involvement of the obtic nerves.

In the cases which we have presented, the relation of the recurrent episodes to infective illness was not always apparent, nor, in an individual case, did the same symptoms and signs necessarily recur. In Case 1 recurrence of neurological symptoms bore a rather questionable relation to chickenpox on one occasion; one episode consisted of ophthalmoplegia, and two of ataxia. The neurological illnesses in Case 2 were clearly related to infection, but the signs and symptoms were different in each case. In Case 3 only the second and last episodes were associated with infection, and in three of these the neurological lesions were at different sites on each occasion.

Despite these points it does seem likely that the recurrent episodes described were precipitated by a sensitivity mechanism. There is, of course, unequivocal evidence of recurrent neurological illness following the administration of serum and vaccines. A patient seen by one of us and later described by Miller and Stanton (1954) gave a history of hay fever. He had had an illness like influenza associated with vertigo, nystagmus, vomiting and paralysis of the right arm, the last symptom persisting for a year; two years later he was given a prophylactic dose of anti-tetanic serum. This was followed by urticaria and pains in the arms. Weakness and wasting of the right shoulder girdle muscles then occurred, with sensory loss over the C5 dermatone on that side. The diaphragm was also paralysed. Brody (1947) described the case of a child who was given three injections of pertussis vaccine, the first during an undiagnosed attack of whooping cough. After each dose an encephalomyelitic illness occurred. There was a fourth attack after an upper respiratory infection, and the child died at the age of $\mathbf{4 3}$ months in a fifth episode after an intradermal injection of pertussis vaccine. It is tempting to speculate on the relation of the syndrome to auto-immunity, the possibility of recognizing adult cases and the exact nosological position which it should occupy. We feel, however, that such considerations must await further clarification of the aetiology and pathogenesis of the demyelinating diseases as a whole, and that no useful purpose would be served by discussion on these lines at the present time.

When differential diagnosis is considered it seems that cases which start in childhood, such as we have described, are unlikely to be examples of multiple sclerosis, the onset of which is rare before the age of 10. When their illness began, the ages of our patients varied from 2 to 9 years. Moreover, the athetosis in Case 2 and the fits in Case 3 are unlike the usual findings in this disease. The symptoms of Schilder's disease or the sudanophilic type of diffuse cerebral sclerosis consist of headache, visual impairment, usually of cortical origin, convulsions, mental impairment and various kinds of paralysis or ataxia. The course may be acute (the onset being sometimes related to preceding infection), subacute or chronic. It is usually steadily progressive to a fatal outcome, and as complete remissions do not occur, differentiation from recurrent encephalomyelitis is not difficult. The same may be said of the leuco-dystrophies, in which there is often a familial incidence that is not seen in the syndrome under discussion. Chronic cerebral abscess may be confused with recurrent encephalomyelitis, more especially because repeated respiratory infections can reactivate the abscess and produce a meningitic reaction. Similar recurrent meningitic infections may occur in cases where a traumatic fistula exists between a nasal sinus and the meninges. Benign neoplasms or third ventricle cysts may give rise to mistakes in diagnosis. It will also be remembered that gliomata sometimes produce remitting symptoms in their early development and that those in brain stem or cerebellum might be difficult to differentiate from the condition which we have described. Angiomata, especially those in the brain stem, can give rise to intermittent symptoms, and as they are liable to cause subarachnoid bleeding this complication could easily lead to further confusion with an encephalitic illness. Thrombosis of a cerebral venous sinus or a cortical vein sometimes occurs during measles. If recurrences should arise in subsequent infections, differentiation from the syndrome under review would be difficult.

Treatment. Because of the possibility of a fatal outcome, the management of children who develop recurrent episodes of encephalomyelitis is of the utmost importance. They should be under strict medical supervision during all their infections, or after contact with an infectious illness. If actual encephalitic symptoms develop, treatment with corticosteroids should be seriously considered. In the case described by Miller (1953) and already quoted, A.C.T.H. was given during the fifth attack; improvement was evident within six hours and no further attacks occurred. His brother, similarly affected at the same time, also reacted favourably to this therapy. Recovery of the retrobulbar 
neuritis in Case 5 was thought to have been hastened by prednisone which was given during each attack.

\section{Summary}

Six cases are reported which, on clinical grounds, appear to be further examples of recurrent encephalomyelitis.

It is suggested that treatment with corticosteroids should be considered in the individual episodes of encephalomyelitis.

We have great pleasure in thanking our colleagues, Drs. John Apley, F. S. W. Brimblecombe, C. Brownridge, A. M. G. Campbell and Brian Webb, who have referred patients to us and allowed their records to be reported.

\section{REFERENCES}

Bogaert, L. van (1950). Post-infectious encephalomyelitis and multiple sclerosis. J. Neuropath. exp. Neurol., 9, 219. multiple sclerosis. J. Neuropath. exp. Neurol., $9,219$. d'encéphalomyélite post-morbilleuse. Presse méd., 40, 141.

Brody, M. (1947). Neurologic complications following the administration of pertussis vaccine. Brooklyn Hosp. J., 5, 107.

Ferraro, A. (1958). Studies on multiple sclerosis. J. Neuropath. exp. Neurol., 17, 278

McAlpine, D. (1946). The problem of disseminated sclerosis. Brain, 69, 233.

Miller, H. G. (1953). Acute disseminated encephalomyelitis treated with A.C.T.H. Brit. med. J., 1, 177.

- (1957). Clinical manifestations of tissue reaction in the nervous system. In Modern Trends in Neurology (second series), nervous system. In Modern Trends in Neurology (second series), ed. D. Williams, p. 164. Butterworth, London.

and Stanton, J. B. (1954). Neurological sequelae of prophylactic inoculation. Quart. J. Med., 23.1.

Stout, R. E. and Karnosh, L. J. (1933). Acute disseminated encephalomyelitis. Its clinical manifestations and sequelae.

J. Amer, med. Ass., 101, 667. 